\title{
Optimization of Enzyme Induced Carbonate precipitation (EICP) cementing solution using Design of Experiments
}

\author{
Rami Alsodi $^{1,2}$, Mohamed G. Arab ${ }^{1,3}$, Abdallah Shanablah ${ }^{1}$, Maher Omar ${ }^{1}$, Mufid Samarai ${ }^{1,2}$ \\ ${ }^{1}$ Department of Civil and Environmental Engineering, College of Engineering, University of Sharjah \\ P. O. Box 27272 Sharjah, Sharjah, UAE \\ U15200111@sharjah.ae.ac; marab@sharjah.ac.ae; shanableh@sharjah.ac.ae; momar@sharjah.ac.ae; \\ samarai@sharjah.ac.ae \\ ${ }^{2}$ Sharjah Research Academy, Government of Sharjah \\ P.O. Box 2580, Sharjah, United Arab Emirates \\ ramy@sra.ae; mufid.samarai@sra.ae \\ ${ }^{3}$ Structural Engineering Department, Faculty of Engineering, Mansoura University \\ Al-Gomhoria Street, Mansoura, Egypt \\ mg_arab@mans.edu.eg
}

\begin{abstract}
Enzyme induced carbonate precipitation (EICP) is a biogeotechnical ground improvement technique that enhance the mechanical properties of the soil by binding the soil particles together through precipitating calcium carbonate at the particles contact points. Taguchi design of experiment technique was implemented to optimize the EICP cementing solution. The analysis suggests that a solution of $3 \mathrm{M}$ Urea, $1.5 \mathrm{M} \mathrm{CaCl}_{2}, 3 \mathrm{~g} / \mathrm{L}$ Urease and $4 \mathrm{~g} / \mathrm{L}$ of milk is optimum for maximum carbonate precipitation. To verify the efficiency of the obtained solution, silica sand was treated with the optimized solution to confirm the effectiveness of the proposed solution. An average compressive strength of 1.22 MPa was achieved using this cementing solution.
\end{abstract}

Keywords: Biogeotechnical, ground improvement, biocementation, EICP, calcium carbonate precipitation.

\section{Introduction}

Enzyme induced carbonate precipitation (EICP) is a method in biogeotechnical engineering used for ground improvement. This improvement technique utilizes only natural, cheap and environmentally friendly materials like urea, calcium chloride and urease enzyme, which makes it a sustainable and environmentally friendly solution for many engineering applications. The method mainly relies on the hydrolysis of urea by plant-extracted urease enzyme to precipitate calcium carbonate in the soil pores. Calcium carbonate works as a binder between soil particles thereby; it enhances the mechanical properties of the treated soil. In this method, a free urease enzyme extracted from agricultural source works as a catalyst for the hydrolysis of urea in the solution, which results in carbonate ion production. In the presence of calcium ions from any salt source, the carbonate ions precipitate as calcium carbonate as a result of the increase in carbonate concentration beyond the level of supersaturation. The EICP solution consists of urea, calcium chloride and urease. Each solution constituent is used at a different concentration in order to maximize the carbonate precipitation. It is important to find the optimum concentration for each constituent of the cementing solution to achieve maximum efficiency in terms of precipitation mass yielded by the solution. Several studies investigated the effect of each constituent concentration on carbonate precipitation.

Yasuhara et al. [1], studied the effect of increasing urea and $\mathrm{CaCl}_{2}$ on the efficiency of the precipitation. The precipitation efficiency was evaluated by calculating the precipitation ratio, which is the ratio of precipitation to theoretical precipitation based on the available amount of calcium chloride, higher precipitation ratio means more efficiency of the solution. Equimolar concentration for urea-CaCl 2 solution was used $(0.5,1.0$ and 1.5 mol $/ \mathrm{L})$ with $10 \mathrm{~g} / \mathrm{L}$ urease concentration. It was concluded that increasing the molarity of urea- $\mathrm{CaCl}_{2}$ solution reduce the precipitation ratio since this high concentration may inhibit the activity of the urease. Moreover, unconfined compressive test of treated soil columns achieved a strength of $400 \mathrm{kPa}$ to $1.6 \mathrm{MPa}$. Neupane et al. [2] evaluated the amount of precipitation of calcium carbonate in transparent polypropylene tubes without soil. A $15 \mathrm{~mL}$ solution of $1: 1$ ratio urea-CaCl 2 with concentrations of $0.5 \mathrm{M}$ 
and $1.0 \mathrm{M}$ were mixed with $15 \mathrm{~mL}$ solution of urease with concentration of $0.5 \mathrm{~g} / \mathrm{L}$ to $4.0 \mathrm{~g} / \mathrm{L}$. The solution was left to react for $24 \mathrm{~h}$, then it was filtered through a filter paper to collect the precipitation. The precipitation on the filter paper and the tubes was dried to measure the total dry mass of precipitation from each combination. The most efficient solution obtained was the mixture of $0.5 \mathrm{M}$ of urea- $\mathrm{CaCl}_{2}$ and $2 \mathrm{~g} / \mathrm{L}$ urease which had a precipitation ratio of $80 \%$. Increasing the urease content to $3 \mathrm{~g} / \mathrm{L}$ increased the precipitation ratio by $10 \%$ only.

Aishwarya and Christy [3], studied the effect of different constituents of the EICP solution on the carbonate precipitation. Varied combinations of urea, $\mathrm{CaCl}_{2}$ and urease were thoroughly mixed and left to cure for 2 hours at $37{ }^{\circ} \mathrm{C}$. The solution was then filtered with a filter paper and the mass of precipitation were measured after drying the filter paper. It was found that a solution of $1.5 \mathrm{M}$ urea, $1.5 \mathrm{M} \mathrm{CaCl}_{2}$ and $0.45 \mathrm{~g} / \mathrm{L}$ urease gives the highest mass of precipitation.

Carmona et al. [4] examined the rate of urea hydrolysis by the urease enzyme for different concentrations solutions. An equimolar solution of urea-CaCl${ }_{2}$ with concentration of $0.25,0.5,0.75,1.0$ and $1.25 \mathrm{~mol} / \mathrm{L}$ was evaluated. The urease enzyme concentration used was $0.1 \mathrm{~g} / \mathrm{L}$. The $10 \mathrm{ml}$ Urea- $\mathrm{CaCl}_{2}$ solution was mixed with a $10 \mathrm{ml}$ urease enzyme solution and left to cure for 14 days. The solution was filtered through a filter paper, then both the tube and filter paper were dried to measure the weight of dry precipitation mass and calculate the precipitation ratio as well. It was found that for urease enzyme concentration of $0.1 \mathrm{~g} / \mathrm{L}$, a concentration of $0.25 \mathrm{~mol} / \mathrm{L}$ for urea-CaCl $\mathrm{C}_{2}$ is optimum for precipitation efficiency, since higher concentrations may inhibit the activity of the urease enzyme.

Simatupang \& Okamura [5] conducted a tube test to evaluate the precipitation efficiency. Using urea to calcium chloride ratio of $1: 1$, concentrations of the reagents where varied from 0.15 to $1 \mathrm{~mol} / \mathrm{L}$. The reagents where mixed with various urease concentrations ( 3 to $35 \mathrm{~g} / \mathrm{L}$ ). The weight of the precipitation was measured at a regular interval by acid washing method. It was found that the time when $100 \%$ precipitation ratio was reached depends on the amount of the added enzyme. A high concentration of urea and calcium chloride relative to the urease concentration may reduce the precipitation efficiency since it will restrict the performance of the urease enzyme.

Almajed et al. [6] investigated the effect of solution concentration used in the EICP solution on the amount of precipitation. 37 tubes containing $20 \mathrm{ml}$ of EICP solutions of different concentrations was used in this study. The concentration of urea varied from $0.25 \mathrm{M}$ to $1.5 \mathrm{M}$, the ratio of calcium chloride to urea was varied from $1: 1$ to $1: 1.75$ and the enzyme concentration ranged from $1 \mathrm{~g} / \mathrm{L}$ to $6 \mathrm{~g} / \mathrm{L}$. The author concluded that that there is strong correlation between the precipitation ratio and the amount of enzyme for a given electric conductivity (EC) of the EICP solution. Based on their study, Almajed et al. [6] recommended to use $1 \mathrm{M}$ of Urea and $0.67 \mathrm{M}$ of Calcium Chloride with $3 \mathrm{~g} / \mathrm{L}$ urease enzyme to achieve the most precipitation efficiency with the minimum enzyme content. The sand soil specimens prepared with this recipe for the EICP cementing solution have showed a maximum strength of $1.2 \mathrm{MPa}$ using percolation technique after 4 cycles of treatment (where the cementing solution is percolated from the top of the specimen).

As shown earlier, EICP cementing solution efficiency depends on the urease enzyme source and activity. Most of the previous studies use pure urease enzyme, the enzyme was reported to account for $57 \%-98 \%$ of the total cost of the EICP cementing solution [6]. In an attempt to reduce treatment cost, researchers examined the use of urease extracted from watermelon seeds and crude extracted soybean for the application of bio-cementation [7-9]. However, few studies have investigated the possibility of using jack bean meal (JBM) as alternative to the expensive high purity urease enzyme extract for the hydrolysis process [10-12]. In this study the use of JBM as source of enzyme has been examined. Due to the complexities arising from EICP's biochemical nature and the interaction between different factors involved in the treatment, the standardization of optimum EICP solution is vaguely defined in the literature and varies between research groups. So, in this study we will study the interaction between different factors that affect EICP cementing solution participation including reagents concentration, JBM concentration and number of curing days.

The analysis will be conducted using Tagushi technique. In this research, the objective is to investigate the effect of concentrations of different EICP cementing solution constituents on the efficiency of precipitation of calcium carbonate with considering the curing time as a factor. The objective of the study will be achieved through modeling the effect of the different parameters using Taguchi design of experiments (DOE) technique. From the results, an optimum recipe will be recommended for the EICP cementing solution. Recommended EICP cementing solution will be examined in enhancing the unconfined compressive strength (UCS) of treated sand soil specimens.

\section{Design of experiments}

Taguchi method is a partial factorial DOE technique that is been used in many engineering applications since it allows the analysis of many factors that have influence on the response, without the need for a large number of experiments. In 
this technique, the variables are classified as controllable variables and uncontrollable variables known as noise, and then based on the response of the experiments the optimum combinations for the controllable variables is determined that have minimum effect transmitted from uncontrollable variables. In the Taguchi approach, a standard orthogonal array is created that minimize the number of experiments used to study the effect of several inputs on a certain output in unbiased manner. In this study, the curing time, the urea concentration and JBM concentration was defined as controllable factors, while the temperature (in the field) was defined as uncontrollable noise factor and the mass of precipitation is the response. The temperature range was assumed based on temperature range encountered in the field in UAE where the study was conducted. The aim is to find an optimum solution to maximize the carbonate precipitation regardless of the curing temperature encountered in the field. Table 1 summarize all the factors included in the study with the range assumed and the levels for each factor. It is important to note here that the rest of the EICP cementing solution constituents were kept constant. The urea to $\mathrm{CaCl}_{2}$ ratio was kept constant at 1:2 while, the ratio between the milk to JBM in the EICP cementing solution was kept as 1:0.75.

Table 1: Factors studied with suggested levels for each factor in Taguchi DOE.

\begin{tabular}{|c|c|c|c|c|c|}
\hline \multicolumn{6}{|c|}{ Controllable factors } \\
\hline \multirow{2}{*}{ Notation } & Factor & Unit & $\mathbf{1}$ & $\mathbf{2}$ & $\mathbf{3}$ \\
\hline $\mathrm{A}$ & curing time & Days & 4 & 7 & 14 \\
\hline $\mathrm{B}$ & urea concentration & Mol/L & 1 & 2 & 3 \\
\hline $\mathrm{C}$ & $\mathrm{JBM}$ concentration & $\mathrm{g} / \mathrm{L}$ & 3 & 4 & 5 \\
\hline \multicolumn{6}{|c|}{ Uncontrollable (Noise factor) } \\
\hline \multicolumn{7}{|c|}{ Temperature } & ${ }^{\circ} \mathrm{C}$ & 20 & 30 & 40 \\
\hline
\end{tabular}

\section{Materials and Methods}

\section{1. Materials}

\section{1. 1. EICP solution}

The EICP solutions were prepared using lab grade urea from fisher with purity of $99.5 \%$, calcium chloride dihydrate, urease active-meal from jack bean meal (JBM) with reported activity of $1500 \mathrm{U} / \mathrm{g}$ from Fisher Scientific and finally, commercially available powdered skimmed milk. The non-fat powder milk has been proposed as stabilizing agent required to stabilize and enhance the performance of the EICP cementing solution by several researchers $[12,13]$. The concentration of milk was added as ratio of the JBM concentration used. The ratio between the milk to JBM in the EICP cementing solution was kept as 1: 0.75 based on the recommendations of Almajed et al. [6].

\section{1. 2. Soil}

Soil used in this study is graded silica sand (ASTM C778), acquired from a French Source natural silica sand with silica content of $99 \%$ according to the manufacturer (Société Nouvelle du Littoral). The soil classified according to the unified soil classification system as poorly graded medium to fine sand (SP). The gradation curve of the tested sand is shown in Fig. 1. It is indicated that the median grain size $\left(D_{50}\right)$, the coefficient of uniformity $\left(\mathrm{C}_{\mathrm{u}}\right)$ and the coefficient of graduation $\left(\mathrm{C}_{\mathrm{c}}\right)$ of the tested soil are $0.36 \mathrm{~mm}, 2.0$, and 1.28 respectively.

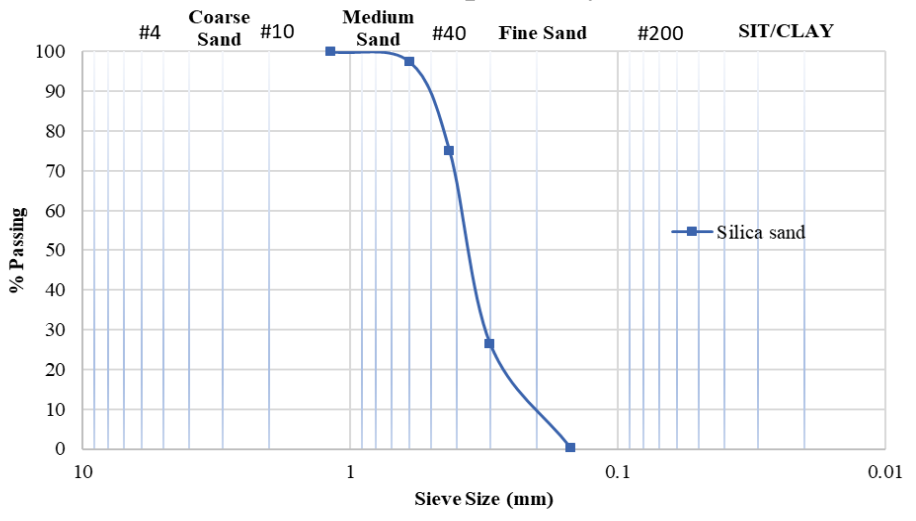

Fig. 1: Grain size analysis for the ASTM C778 Graded Silica Sand. 


\section{2. Methodology}

\section{2. 1. Tube Tests}

To investigate the effect of the concentration of each constituent used in the EICP solution, 81 solutions were prepared based on Taguchi orthogonal array design of experiments. For a design of 3 factors and 3 levels, L27 ( $\left.3^{3}\right)$ array were utilized to create a matrix that will require performing 27 experiments to analyze the effect of the factors on the output at 3 levels of temperature $\left(20^{\circ} \mathrm{C}, 30^{\circ} \mathrm{C}\right.$ and $\left.40{ }^{\circ} \mathrm{C}\right) .27$ tube samples containing $20 \mathrm{ml}$ of EICP solution without any soil were prepared in small glass tubes. The urea to $\mathrm{CaCl}_{2}$ ratio was kept constant at 1:2 as stated earlier. The 27 solutions for each curing temperature were prepared as per the L27 array obtained from the generated matrix using Minitab ${ }^{\mathrm{r}} 17$ software. Table 2 presents the generated matrix from Minitab. In Taguchi method, a noise factors is a factor that is difficult to or expensive to control, such as environmental factors. The temperature was considered uncontrollable (noise) factor, since the temperature is uncontrollable factor in the field.

Table 2: L27 orthogonal array for the concentrations of the solutions.

\begin{tabular}{|c|c|c|c|}
\hline ID & Curing Time (days) & Urea (Mol/L) & JBM $(\mathbf{g} / \mathbf{L})$ \\
\hline 1 & 4 & 1 & 3 \\
\hline 2 & 4 & 2 & 4 \\
\hline 3 & 4 & 3 & 5 \\
\hline 4 & 7 & 1 & 3 \\
\hline 5 & 7 & 2 & 4 \\
\hline 6 & 7 & 3 & 5 \\
\hline 7 & 14 & 1 & 3 \\
\hline 8 & 14 & 2 & 4 \\
\hline 9 & 14 & 3 & 5 \\
\hline 10 & 14 & 1 & 4 \\
\hline 11 & 14 & 2 & 5 \\
\hline 12 & 14 & 3 & 3 \\
\hline 13 & 4 & 1 & 4 \\
\hline 14 & 4 & 2 & 5 \\
\hline 15 & 4 & 3 & 3 \\
\hline 16 & 7 & 1 & 4 \\
\hline 17 & 7 & 2 & 5 \\
\hline 18 & 7 & 3 & 3 \\
\hline 19 & 7 & 1 & 5 \\
\hline 20 & 7 & 2 & 3 \\
\hline 21 & 7 & 3 & 4 \\
\hline 22 & 14 & 1 & 5 \\
\hline 23 & 14 & 2 & 3 \\
\hline 24 & 14 & 3 & 4 \\
\hline 25 & 4 & 1 & 5 \\
\hline 26 & 4 & 3 & 3 \\
\hline 27 & 4 & & 4 \\
\hline & & 2 & \\
\hline & 7 & 3 & 3 \\
\hline
\end{tabular}

The EICP tube samples were prepared in small tube glasses, labelled with concentration and curing period according to the previous table, and then closed by their caps to prevent evaporation and moisture loss as well as avoiding spilling, Fig. 2 shows the tubes used in this test. The test tubes were incubated in a closed shaking incubator at $30 \mathrm{rpm}$, with the ability to control temperature for curing. 


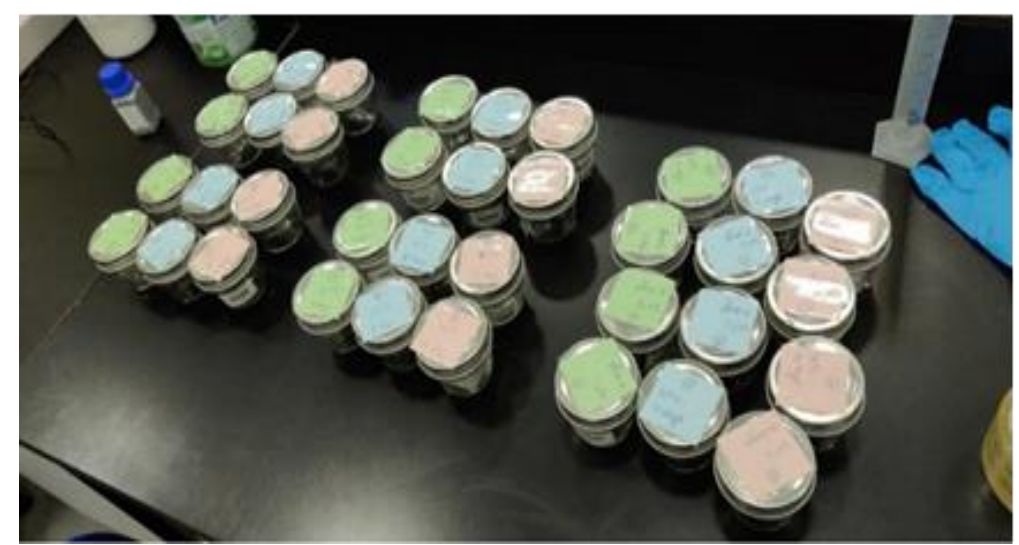

Fig. 2: Glass tube labeled to identify the EICP solution used and curing time.

After the curing period, each solution was filtered through a filter paper to collect any suspended precipitation before diposal, and then both the filter paper and glass tubes were dried in the oven for 24 hours at $50{ }^{\circ} \mathrm{C}$ and weighed at the end to determine the carbonate precipitation. Each glass container was weighted before adding the EICP solution to be able to get the weight of the carbonate precipitation after curing time. Fig. 2 show the precipitant at the bottom of the glass tube after drying.

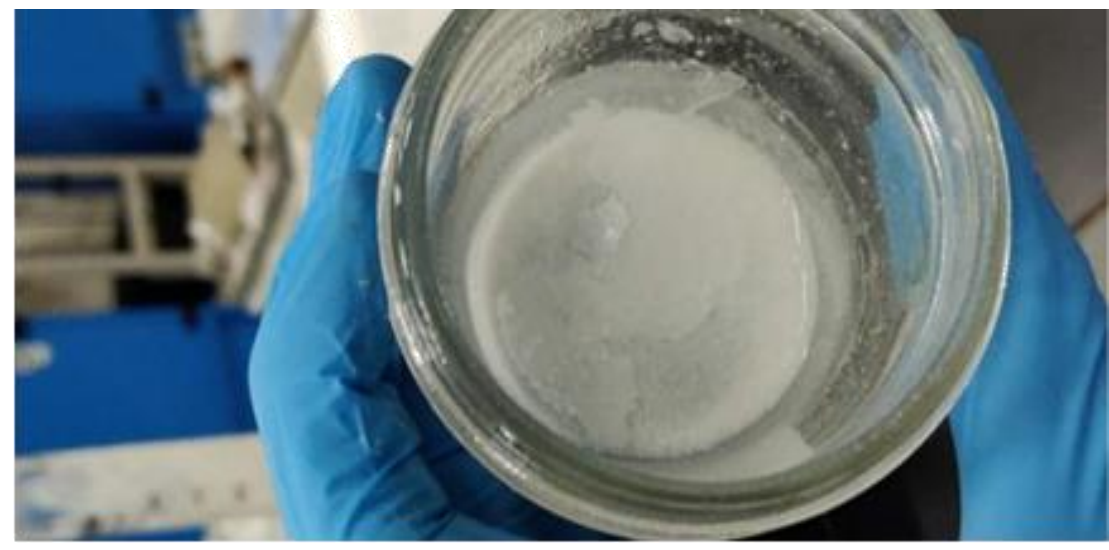

Fig. 3: Carbonate precipitant at the bottom of the glass tube.

\section{2. 2. Soil Specimen Preparation}

The obtained optimum EICP cementing solution was used to treat 3 replicates of sand. The treated specimen was prepared by mixing $356 \mathrm{~g}$ of soil with $65 \mathrm{ml}$ of EICP solution. The soil mix was compacted inside PVC tube with $5 \mathrm{~cm}$ inner diameter and $10 \mathrm{~cm}$ height. The wet sand where placed in the mold in 3 layers in order to achieve a relative density of about $45 \%$. The columns were allowed to cure at room temperature for 4 days. After curing, the samples were extracted from the PVC tubes and flushed with one pore volume of water and then oven-dried at $50{ }^{\circ} \mathrm{C}$ to get rid of accesses water. The specimens were then tested for unconfined compression test with a rate of $0.50 \%$ axial strain per minute.

\section{Results and Discussion}

\section{1. Tube Tests results}

The aim of the study is to find the optimum EICP cementing solution constituents that gives the highest response (highest carbonate precipitation) possible by maximizing the signal to noise ratio at the lowest standard deviation possible. Moreover, for the design to be robust, the value of precipitation must be insensitive to the change in temperature. The results from tube test were analyzed to choose the optimum EICP solution based on the maximum obtained precipitation mass. The analysis of the results was conducted using Minitab ${ }^{\mathrm{r}} 17$ software at a $95 \%$ level of confidence $(\alpha=5 \%)$. The main effect plots were used to determine the optimum level for each factor. The results of signal to noise ratio are shown in Fig. 4, and the residual plot is shown in Fig. 5 to insure the accuracy of the model data. 
Table 3: Results of precipitation mass for each temperature.

\begin{tabular}{|c|c|c|c|c|c|c|}
\hline & \multicolumn{3}{|c|}{ Controllable factors } & \multicolumn{3}{c|}{ Temperature } \\
\hline ID & Curing Time (days) & Urea (Mol/L) & JBM (g/L) & $\mathbf{2 0}{ }^{\circ} \mathbf{C}$ & $\mathbf{3 0}{ }^{\circ} \mathbf{C}$ & $\mathbf{4 0}{ }^{\circ} \mathbf{C}$ \\
\hline 1 & 4 & 1 & 3 & 3.1 & 3.1 & 1.9 \\
\hline 2 & 4 & 2 & 4 & 3.6 & 2.1 & 2.5 \\
\hline 3 & 4 & 3 & 5 & 4.1 & 3.1 & 3.8 \\
\hline 4 & 7 & 1 & 3 & 1.1 & 1 & 1.37 \\
\hline 5 & 7 & 2 & 4 & 1.4 & 1.7 & 2.32 \\
\hline 6 & 7 & 3 & 5 & 2.8 & 4.7 & 3.56 \\
\hline 7 & 14 & 1 & 3 & 1.2 & 1.1 & 0.93 \\
\hline 8 & 14 & 2 & 4 & 3 & 1.6 & 1.53 \\
\hline 9 & 14 & 3 & 5 & 2.3 & 4 & 3.23 \\
\hline 10 & 14 & 1 & 4 & 1.4 & 1.5 & 1.43 \\
\hline 11 & 14 & 2 & 5 & 1.6 & 1.5 & 1.83 \\
\hline 12 & 14 & 3 & 3 & 4 & 2.9 & 1.63 \\
\hline 13 & 4 & 1 & 4 & 1.3 & 1.3 & 1.4 \\
\hline 14 & 4 & 2 & 5 & 5.7 & 1.6 & 2.7 \\
\hline 15 & 4 & 3 & 3 & 6 & 2.9 & 3.1 \\
\hline 16 & 7 & 1 & 4 & 1.4 & 1.4 & 2.29 \\
\hline 17 & 7 & 2 & 5 & 2.1 & 1.4 & 2.11 \\
\hline 18 & 7 & 3 & 3 & 4 & 4.6 & 4.61 \\
\hline 19 & 7 & 1 & 5 & 1.2 & 0.6 & 2.03 \\
\hline 20 & 7 & 2 & 3 & 2 & 0.8 & 2.27 \\
\hline 21 & 7 & 3 & 4 & 2.6 & 3.3 & 6.22 \\
\hline 22 & 14 & 1 & 5 & 0.8 & 0.5 & 1.13 \\
\hline 23 & 14 & 2 & 3 & 1.3 & 2.1 & 1.53 \\
\hline 24 & 14 & 3 & 4 & 3.5 & 4.2 & 3.13 \\
\hline 25 & 4 & 1 & 5 & 1.5 & 0.8 & 1.6 \\
\hline 26 & 4 & 3 & 4 & 5.1 & 3.9 & 3.3 \\
\hline 27 & 4 & & & & & \\
\hline & & 2 & 3 & 2.1 & 3.5 & 2.7 \\
\hline
\end{tabular}

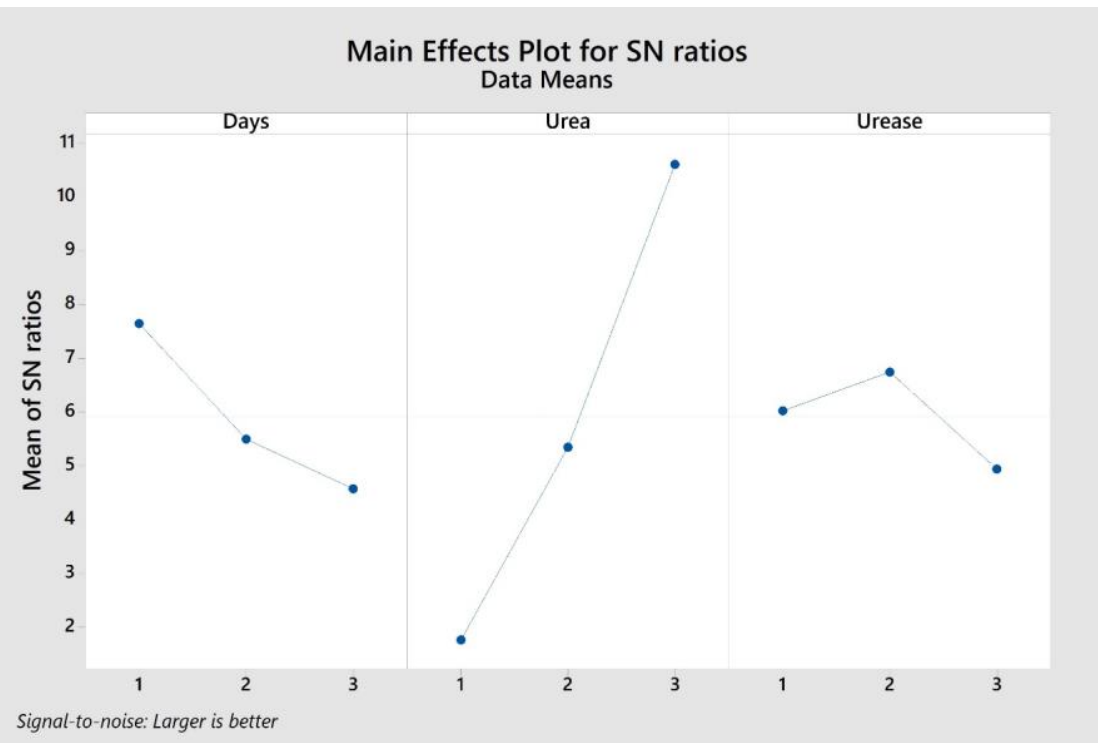

Fig. 4: Main effect plot of Signal-to-noise (SN) ratio for the response of precipitation mass. 


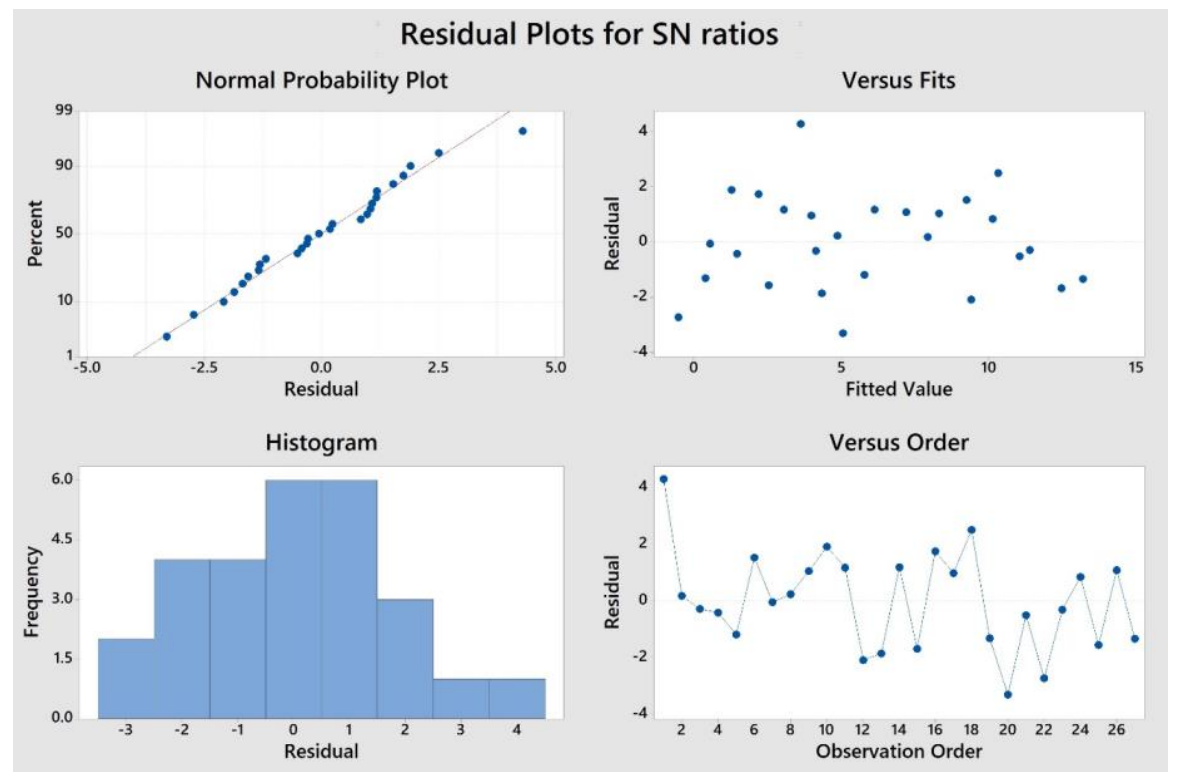

Fig. 5: Residual plots for the Signal-to-noise (SN) ratio.

The relative influence of each factor is determined by using the analysis of variance method (ANOVA). Since $95 \%$ confidence level is used, p-value less than 0.05 will indicate the significance of the factor. Table 3 show the data for ANOVA analysis.

Table 3: ANOVA Data analysis.

\begin{tabular}{|c|c|c|c|c|c|c|}
\hline Source & DF $^{\mathbf{1}}$ & Seq SS $^{\mathbf{2}}$ & Adj SS $^{\mathbf{3}}$ & Adj MS $^{\mathbf{4}}$ & F & P \\
\hline Curing Time & 2 & 44.60 & 44.60 & 22.3 & 5.76 & 0.011 \\
\hline Urea Concentration & 2 & 356.47 & 356.47 & 178.2 & 46.01 & 0.000 \\
\hline JBM Concentration & 2 & 14.84 & 14.84 & 7.422 & 1.92 & 0.173 \\
\hline Residual Error & 20 & 77.48 & 77.48 & 3.8 & & \\
\hline Total & 26 & 493.40 & & & & \\
\hline
\end{tabular}

${ }^{1}$ DF: Total Degrees of Freedom

${ }^{2}$ Seq SS: Sequential sums of squares

${ }^{3}$ Adj SS: Adjusted sums of squares

${ }^{4}$ Adj MS: Adjusted mean squares

ANOVA results indicates that the molarity of the reagents, urea and $\mathrm{CaCl}_{2}$ are the most influencing factors on the precipitation mass. The P-value indicates that the concentration of the JBM is insignificant factor. Since the JBM is the most expensive component in the EICP cementing solution, it is preferred to keep the urease enzyme concentration minimum. Moreover, the obtained data show that the precipitation mass is decreasing with increase period of curing. This can be attributed to the accumulation of the ammonium chloride in the tube which may have a negative effect on the carbonate precipitation. This may suggest the importance of flushing the by-products of the reaction from the treated soils after 4 days of curing. The results of the ANOVA analysis suggest an EICP solution with $3 \mathrm{M}$ urea, $3 \mathrm{~g} / \mathrm{L} \mathrm{JBM}$ and $4 \mathrm{~g} / \mathrm{L}$ skimmed milk as the optimum EICP cementing solution that gives the maximum precipitation mass possible regardless of the curing temperature. The results presented in this study may contradict with several studies reported decrease in carbonate precipitation due to the increase in urea and salt concentration. The previous studies have attributed this reduction to the denaturalization of the urease due to the increase in regent's concentration. While in this study JBM was used as urease enzyme while most of previous studies have used pure urease enzyme as a catalyst for the hydrolysis process. This can be further understood from the study reported by Larsen et al. [12] on the effect of using JBM in the hydrolysis of urea. In their study a comparison was conducted between JBM and lab grade urease enzyme in catalyzing the hydrolysis reaction. A ten-fold increase in calcium carbonate precipitation yield was found using jack bean meal as catalyst compared to lab grade urease enzyme. Moreover, Larsen et al. [12] showed that JBM has 35\% higher protein than 
lab grade pure urease enzyme which help in protecting the enzyme from denaturalization in EICP solution with high urea and calcium chloride concentration. This may illustrate the higher carbonate precipitation in the case of EICP solution contains higher reagents concentration compared to the EICP solution with lower urea and $\mathrm{CaCl}_{2}$. Few studies in the literature have studied the effect of the reaction time on the carbonate precipitation in EICP solution. Several studies have reported that four days of curing were enough to achieve carbonate precipitation close to the maximum theoretical carbonate precipitation in the soil sample [6,14]. The study herein confirm that 4 days were enough for the hydrolysis reaction to conclude.

\section{2. UCS Results}

Soil samples were treated with EICP cementing solution that yielded the maximum carbonate precipitation. The EICP cementing solution was as follows ( $3 \mathrm{M}$ Urea, $1.5 \mathrm{M} \mathrm{CaCl}_{2}, 3 \mathrm{~g} / \mathrm{L}$ Urease and $4 \mathrm{~g} / \mathrm{L}$ of milk). The treated soil specimens were tested for unconfined compressive strength. The results of the UCS test for the three samples are shown in Fig. 6, knowing that the strain is corrected according to ASTM D2166. A maximum peak compressive strength of about $1.25 \mathrm{MPa}$ compressive strength for the sand treated specimens was obtained.

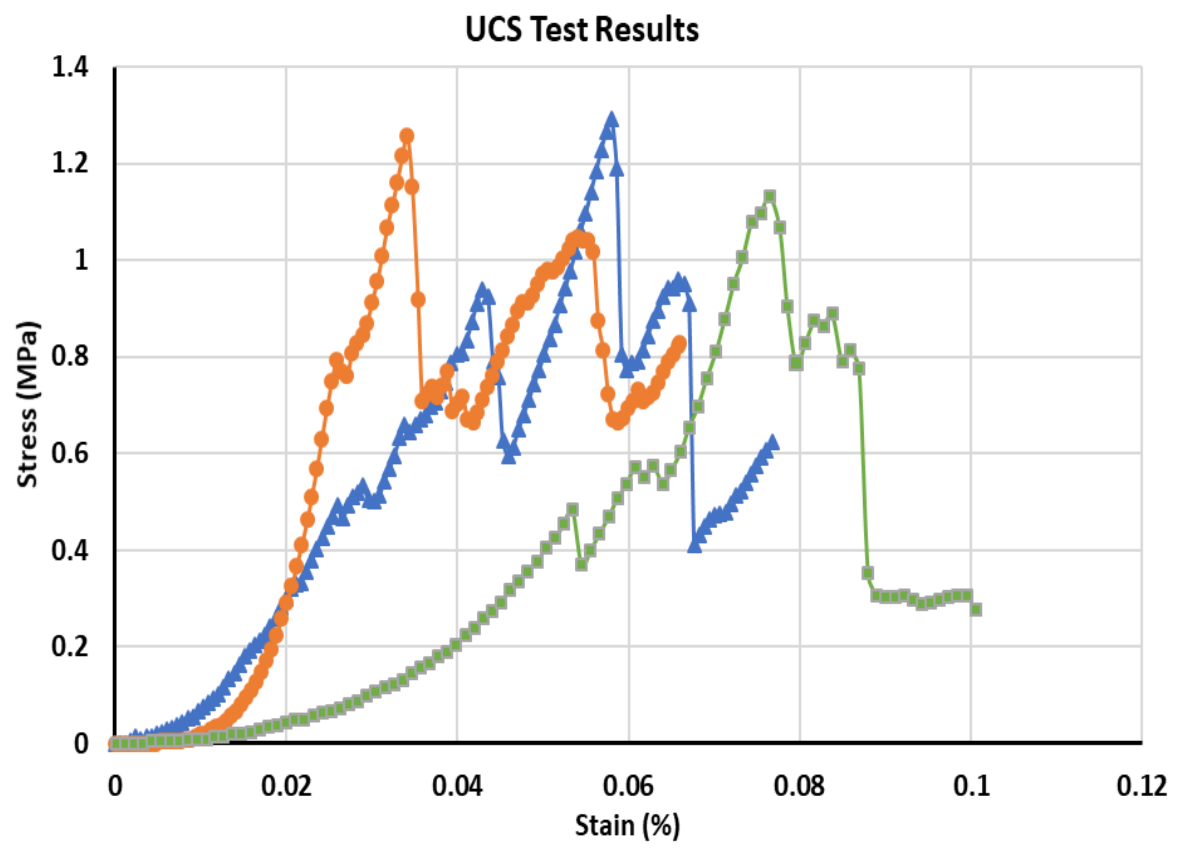

Fig. 6: UCS in MPa obtained for the three replicates.

\section{Conclusions}

In this study Taguchi DOE technique was applied to optimize the EICP cementing solution in terms of precipitation of carbonate content. The DOE technique was used to design a partial factorial experiment in order to investigate the influence of the curing time, urea concentration and JBM concentration under uncontrollable factor influence (temperature). The JBM was used as a source of enzyme instead of pure urease enzyme. The ANOVA statistical analysis of the response (mass of carbonate precipitation) revealed that the reagents concentration has the most significant effect on the carbonate precipitation. However, the increase in curing time have shown a slightly negative effect on the precipitation mass. This is may be attributed to the high molarity of the urea which may have resulted in acidity of the solution and reverse reaction. This confirm that 4 days of curing is adequate and flushing of the cementing solution may be required to get rid of the ammonium chloride byproduct from the solution.

This study suggests that a solution of $3 \mathrm{M}$ Urea, $1.5 \mathrm{M} \mathrm{CaCl}_{2}, 3 \mathrm{~g} / \mathrm{L}$ Urease and $4 \mathrm{~g} / \mathrm{L}$ of milk, is recommended for optimal carbonate precipitation. The obtained optimum cementing solution was used to treat soil specimens to confirm the efficiency of the proposed approach for soil treatment. The soil specimen treated with the obtained recommended solution attained a compressive strength of about $1.25 \mathrm{MPa}$. 


\section{Limitations}

It is important to note that this study is a preliminary study that was conducted an assumed ratio of urea to calcium chloride of 1:2. Also, jack bean meal was used as source of enzyme. This may suggest that the recommended EICP recipe is only valid in the range studied in the current study. Also, the effect of soil type and properties were not thoroughly studied herein. The soil type and properties will have significant effect on the selection of the optimum EICP recipe.

\section{Acknowledgments}

This work has been supported by the University of Sharjah (UoS) and the Sharjah Research Academy (SRA) in the United Arab Emirates under a special agreement (MoU) signed by the parties involved under the number 150443. The authors are grateful to this support.

\section{References}

[1] H. Yasuhara, D. Neupane, K. Hayashi, M. Okamura, "Experiments and predictions of physical properties of sand cemented by enzymatically-induced carbonate precipitation," Soils Found. vol. 52, pp. 539-549, 2012.

[2] D. Neupane, H. Yasuhara, N. Kinoshita, T. Unno, "Applicability of Enzymatic Calcium Carbonate Precipitation as a Soil-Strengthening Technique," J. Geotech. Geoenvironmental Eng., vol. 139, pp. 2201-2211, 2013.

[3] A. Aishwarya, A. Christy, "Bio cemented Sands," Indian Geotech. Conf. 2017 GeoNEst, pp. 14-17, 2017.

[4] J. P. S. F. Carmona, P. J. V. Oliveira, L. J. L. Lemos, "Biostabilization of a Sandy Soil Using Enzymatic Calcium Carbonate Precipitation," Procedia Eng., vol. 143, pp. 1301-1308, 2016.

[5] M. Simatupang, M. Okamura, Liquefaction resistance of sand remediated with carbonate precipitation at different degrees of saturation during curing, Soils Found. 57 (2017) 619-631. doi:10.1016/j.sandf.2017.04.003.

[6] A. Almajed, H. K. Tirkolaei, E. Kavazanjian, "Baseline Investigation on Enzyme-Induced Calcium Carbonate Precipitation," J. Geotech. Geoenvironmental Eng., vol. 144, 2018.

[7] Y. Gao, J. He, X. Tang, J. Chu, "Calcium carbonate precipitation catalyzed by soybean urease as an improvement method for fine-grained soil," Soils Found., 2019.

[8] N. Javadi, H. Khodadadi, N. Hamdan, E. Kavazanjian, "EICP Treatment of Soil by Using Urease Enzyme Extracted from Watermelon Seeds," Geotech. Spec. Publ., pp. 115-124, 2018.

[9] R. A. N. Dilrukshi, J. Watanabe, S. Kawasaki, "Sand cementation test using plant-derived urease and calcium phosphate compound," Mater. Trans., vol. 56, pp. 1565-1572, 2015.

[10] M. A. Arnold, S. A. Glazier, "Jack bean meal as biocatalyst for urea biosensors," Biotechnol. Lett. vol. 6, pp. $313-$ 318, 1984.

[11] S. Handley-Sidhu, E. Sham, M. O. Cuthbert, S. Nougarol, M. Mantle, M. L. Johns, L. E. Macaskie, J. C. Renshaw, "Kinetics of urease mediated calcite precipitation and permeability reduction of porous media evidenced by magnetic resonance imaging," Int. J. Environ. Sci. Technol., vol. 10, pp. 881-890, 2013.

[12] J. Larsen, M. Poulsen, T. Lundgaard, M. Agerbaek, "Plugging of Fractures in Chalk Reservoirs by EnzymeInduced Calcium Carbonate Precipitation," SPE Prod. Oper., vol. 23, pp. 478-483, 2008.

[13] S. S. Bang, S. Bang, S. Frutiger, L. M. Nehl, C. L. Beth, "Application of Novel Biological Technique in Dust Suppression," TRB 2009 Annu. Meet., 2009.

[14] A. Almajed, H. K. Tirkolaei, E. Kavazanjian, N. Hamdan, "Enzyme Induced Biocementated Sand with High Strength at Low Carbonate Content," Sci. Rep. 9, pp. 1-7, 2019. 